\title{
Diketopiperazines as Cross-Communication Quorum-Sensing Signals between Cronobacter sakazakii and Bacillus cereus
}

\author{
Matheus R. Bofinger, Lucas S. de Sousa, José E. N. Fontes, and Anita J. Marsaioli*ie \\ Institute of Chemistry, University of Campinas, P.O. Box 6154, 13084-971 Campinas, SP, Brazil
}

Supporting Information

ABSTRACT: Herein, we reveal a second quorum-sensing system produced by Cronobacter sakazakii. A cyclo(L-Pro-L-Leu) diketopiperazine, detected in pure and mixed cultures of $C$. sakazakii and Bacillus cereus explains the coexistence of both in the same industrial environments. The molecule was identified by gas chromatography-mass spectrometry (GC-MS), ${ }^{1} \mathrm{H}$, and ${ }^{13} \mathrm{C} \mathrm{NMR}$, including 2D NMR (correlation spectroscopy, heteronuclear multiple bond correlation, and heteronuclear single quantum correlation), and the absolute configuration was compared with that of four synthetic standards produced by solid phase peptide synthesis using a chiral column on a GC-flame ionization detection. This article provides a new method to determine the absolute configuration of cyclo(Pro-Leu) diketopiperazine replacing the joint use of ${ }^{1} \mathrm{H}$ NMR and Marfey's method.

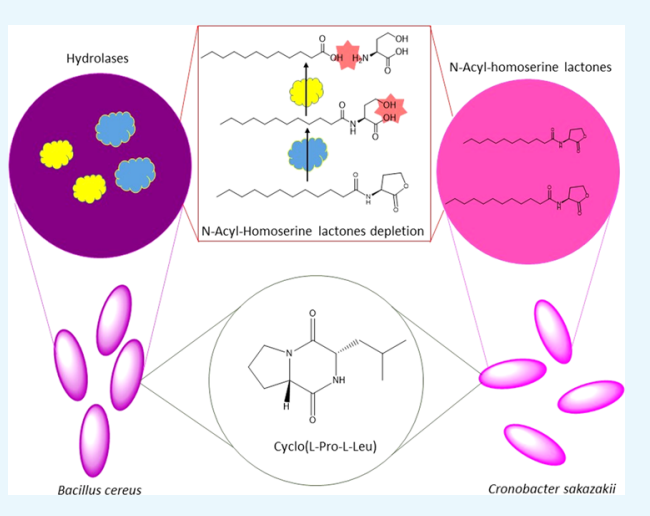

\section{INTRODUCTION}

Cronobacter sakazakii, a Gram-negative, yellow-pigmented, rodshaped, and facultatively anaerobic bacterium, is an opportunistic pathogen that is life-threatening for newborns and elderly adults. ${ }^{1}$ This microorganism is naturally found in the environment and is present in dry foods such as powdered milk, spices, teas, and starches, surviving desiccated conditions. This bacterium can adhere to surfaces, be soaked in an exopolysaccharide matrix (biofilm), and be protected from neighboring threats. ${ }^{2}$ The biofilm formation is controlled by low-molecular-weight molecules in a process of intercommunication called quorum-sensing (QS), and it is known that Gramnegative bacteria are likely to communicate by producing acylhomoserine lactones (AHL). ${ }^{3}$ C. sakazakii is known to produce 3-oxo-hexanoyl-HSL, 3-oxo-octanoyl-HSL, ${ }^{4}(S)$-N-heptanoylHSL, (S)-N-dodecanoyl-HSL, $(S)$ - $N$-tetradecanoyl-HSL, ${ }^{5}$ and short chain acyl-HSL ${ }^{6}$ for $\mathrm{QS}$. The exopolysaccharide matrix can shelter other microorganisms like Bacillus cereus, which is a Gram-positive bacterium and also an infecting agent that causes intestinal and nonintestinal infections in humans; it is commonly associated with food poisoning, ${ }^{7}$ causing acute diarrheal disease, which is related to the production and secretion of a variety of hemolysins, phospholipases, and toxins. ${ }^{7}$ This spore-forming bacterium withstands low temperatures, making the control of its contamination and biofilm formation on plastics, glasses, wool, and inox steel difficult, which impacts public health and the economy. ${ }^{8,9}$ Some Bacillus $s p$. have been investigated for secondary metabolites, revealing the presence of cyclic dipeptides, called 2,5-diketopiperazines (DKPs), used as antifungal and antibacterial agents. Bacillus cereus, from an entomopathogenic nematode, produces cyclo(LPro-L-Arg) with antibacterial and antitumor actions, ${ }^{10}$ and $B$. cereus subsp. thuringiensis produces an antifungal cyclo(L-Pro-
D-Leu). ${ }^{11}$ The four isomers occur in nature, however, their optical rotation data are highly unreliable, thus preventing a rapid absolute configuration determination. ${ }^{12-14}$

Araujo and co-workers ${ }^{5}$ studied C. sakazakii and B. cereus in a co-culture and detected C. sakazakii's acyl-homoserine lactone depletion by $B$. cereus enzymes (acyl-HSL lactonase and acylhomoserine acylase). However, this depletion did not inhibit the biofilm formation or $C$. sakazakii growth, suggesting the presence of alternative signaling molecules for the C. sakazakii and B. cereus QS system. Therefore, the aim of this work is to reveal the cross-talking signal system between $C$. sakazakii and B. cereus.

\section{RESULTS AND DISCUSSION}

The absence of biofilm inhibition in co-cultures of C. sakazakii and $B$. cereus, as previously reported, was intriguing. Thus, the presence of a secondary communication exclusive to $C$. sakazakii and a cross-communication system between both species, was the focus of the present investigation. Consequently, C. sakazakii and B. cereus were cultivated individually, and co-cultivated, to evaluate the second mechanism of intraand inter-species chemical communication. The cell-free supernatants were extracted with ethyl acetate, and a common group of DKPs was effectively detected that was completely unaccounted for in our previous investigation. Isolation of the polar fractions was achieved using a silica column eluted with ethyl acetate; methanol allowed the identification of the major DKP as the cyclic dipeptide cyclo(Pro-Leu) (Figure 1). The

Received: December 16, 2016

Accepted: March 6, 2017

Published: March 16, 2017 
retention time and fragmentation pattern were consistent with data found in the literature. ${ }^{15,16}$

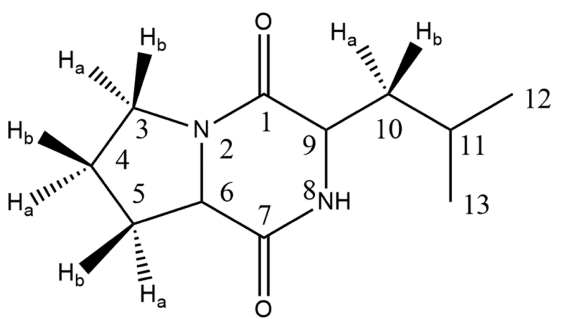

Figure 1. Structure of cyclo(Pro-Leu).

NMR data confirmed the structure of the DKP and showed the ${ }^{1} \mathrm{H}$ and ${ }^{13} \mathrm{C}$ shifts for cyclo(Pro-Leu) isolated from $B$. cereus, C. sakazakii, and the culture of both bacteria (see Supporting Information). 2,5-DKPs are QS molecules commonly found in Gram-positive bacteria and are not usually present in Gram-negative bacteria such as C. sakazakii, where the QS is based on AHL. However, previous studies have shown that DKPs can modulate regulatory proteins for gene expression, substituting AHLs in Gram-negative bacteria's communication. ${ }^{17,18}$ From this point of view, this work shows that despite the $B$. cereus enzymes destroying $C$. sakazakii's AHLs, both B. cereus and C. sakazakii share a common signal for communication, the cyclo(Pro-Leu). Following this discovery, a few pending questions remained unanswered. The most important question was the absolute configuration of the cyclo(Pro-Leu) and whether this was important for the intercrossing communication. The first attempts to determine the absolute configuration employing specific optical rotation were complicated by the broad range of values of specific optical rotations reported in the literature (Table 1). An additional drawback was the lack of a rapid chiral chromatographic method to check the enantiopurity of the samples.

The optical rotation $\left([\alpha]_{\mathrm{D}}\right)$ values were mainly dependent on the absolute configuration of proline in proline-based DKPs. Negative $[\alpha]_{\mathrm{D}}$ values were observed for L-proline DKPs, and

Table 1. Optical Rotation Data for Cyclo(Pro-Leu) Isomers

\begin{tabular}{|c|c|c|c|}
\hline DKPs & $\begin{array}{l}{[\alpha]_{\mathrm{D}}} \\
(\mathrm{deg})\end{array}$ & solvent & references \\
\hline cyclo(L-Pro-L-Leu) & -109 & $\mathrm{EtOH}$ & 12 \\
\hline cyclo(L-Pro-L-Leu) & -124 & $\mathrm{EtOH}$ & 12 \\
\hline cyclo(L-Pro-L-Leu) & -143 & $\mathrm{EtOH}$ & 19 \\
\hline cyclo(L-Pro-L-Leu) & -142 & $\mathrm{EtOH}$ & 20 \\
\hline cyclo(L-Pro-L-Leu) & -88 & $\mathrm{EtOH}$ & 21 \\
\hline cyclo(L-Pro-L-Leu) & -133 & $\mathrm{EtOH}$ & 22 \\
\hline cyclo(L-Pro-L-Leu) & -156 & $\underset{1: 1}{\mathrm{NaOH}}$ in $\mathrm{MeOH} / \mathrm{H}_{2} \mathrm{O}$ & 23 \\
\hline cyclo(L-Pro-L-Leu) & -89 & $\mathrm{MeOH}$ & 24 \\
\hline cyclo(L-Pro-L-Leu) & -105.8 & $\mathrm{MeOH}$ & 25 \\
\hline cyclo(L-Pro-L-Leu) & -91.3 & $\mathrm{H}_{2} \mathrm{O}$ & 26 \\
\hline cyclo(L-Pro-D-Leu) & -78 & $\mathrm{EtOH}$ & 27 \\
\hline cyclo(L-Pro-D-Leu) & -78.3 & $\mathrm{MeOH}$ & 28 \\
\hline cyclo(L-Pro-D-Leu) & -91.2 & $\underset{1: 1}{\mathrm{NaOH} \text { in } \mathrm{MeOH} / \mathrm{H}_{2} \mathrm{O}}$ & 23 \\
\hline cyclo(L-Pro-D-Leu) & -38 & $\mathrm{MeOH}$ & 13 \\
\hline cyclo(D-Pro-L-Leu) & +35 & $\mathrm{EtOH}$ & 29 \\
\hline cyclo(D-Pro-L-Leu) & +34 & $\mathrm{CHCl}_{3}$ & 14 \\
\hline cyclo(D-Pro-D-Leu) & +152 & $\mathrm{EtOH}$ & 12 \\
\hline
\end{tabular}

positive $[\alpha]_{\mathrm{D}}$ for D-proline DKPs. Additionally, the magnitude was variable, but L-Pro-L-Leu showed higher negative values and L-Pro-D-Leu showed lower negative values of $[\alpha]_{\mathrm{D}}$. The same result was observed for D-proline derivatives, where $\mathrm{D}$ Pro-D-Leu presented higher positive values and D-Pro-L-Leu presented lower positive values. $^{30}$

Comparing the optical rotation of the standards and natural samples, we became aware that different amounts of stereoisomers were present in the mixtures. The $B$. cereus cyclo(ProLeu) had an $[\alpha]_{\mathrm{D}}$ of -28 , and C. sakazakii cyclo(Pro-Leu) had an $[\alpha]_{\mathrm{D}}$ of -21 , but the mixed culture had an $[\alpha]_{\mathrm{D}}$ of -27 . The results were clear but not conclusive. Other procedures were needed to determine the absolute configuration.

Many literature reports ${ }^{11,24,31,32}$ have utilized Marfey's method for enantiomeric identification, which consists of hydrolysis and derivatization using a chiral compound (1fluoro-2,4-dinitrophenyl-5-L-alanine amide), and high-performance liquid chromatography elution in a silica gel column. ${ }^{33}$ This method has been very effective in revealing the absolute configurations of the amino acids, which are the 2,5diketopiperazine components. However, the method depends on hydrolysis and derivatization of the DKPs, which is a timedemanding procedure. The use of gas chromatography (GC) is expected to be less demanding but requires the selection of a column with effective enantio- and diastereodiscrimination. Thus, to investigate the enantiodiscrimination of cyclo(ProLeu) by the available chiral columns, we either had to have racemic standards or pure samples of the four isomers, that is, cyclo(D-Pro-D-Leu), cyclo(L-Pro-L-Leu), cyclo(L-Pro-D-Leu), and cyclo(D-Pro-L-Leu).

Optimization of the chiral gas chromatographical method was undertaken with the four stereoisomeric standards, which are not commercially available, and were obtained by solid phase synthesis. Remarkably, these molecules are able to epimerize, and this phenomenon involves a change of configuration at just one of several chiral centers present in the molecule (Scheme 1). As observed by Adamczeski et al., ${ }^{30}$ epimerization occurred preferentially at $\mathrm{H} 6$ with DKPs containing proline in experiments where D-prolyl-L-norvaline went from +91 to +81 in alkaline solution $(0.01 \mathrm{M} \mathrm{NaOH}$ in

\section{Scheme 1. Stereoisomers of Cyclo(Pro-Leu $)^{a}$}

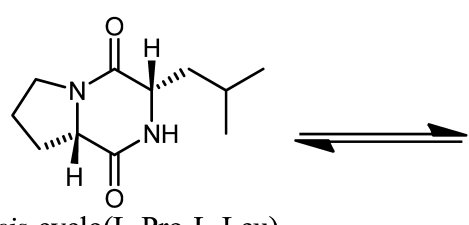<smiles>CC(C)C[C@H]1NC(=O)[C@H]2CCCN2C1=O</smiles>

cis-cyclo(L-Pro-L-Leu) trans-cyclo(D-Pro-L-Leu)<smiles>CC(C)C[C@@H]1NC(=O)[C@@H]2CCCN2C1=O</smiles>
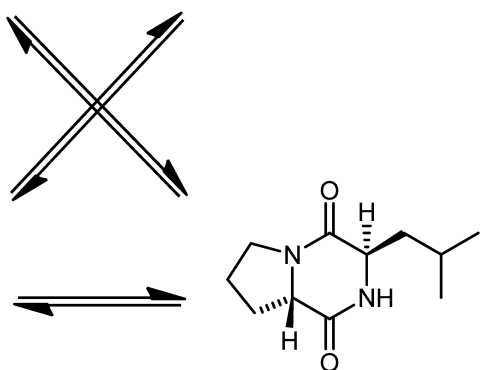

cis-cyclo(D-Pro-D-Leu)

trans-cyclo(L-Pro-D-Leu)

${ }^{a}$ Adapted from ref 34 . 
Table 2. Retention Times, Relative Quantification and Optical Rotations of Cyclo(Pro-Leu) Synthetic Standards

\begin{tabular}{cccccccc} 
& & & \multicolumn{5}{c}{ cyclo(Pro-Leu } \\
\cline { 3 - 6 } standard & retention time $(\min )^{a, b}$ & relative retention time $(\mathrm{RRT})^{a, c}$ & $(\mathrm{~L}-\mathrm{L})(\%)$ & $(\mathrm{L}-\mathrm{D})(\%)$ & $(\mathrm{D}-\mathrm{L})(\%)$ & $(\mathrm{D}-\mathrm{D})(\%)$ & {$[\alpha]_{\mathrm{D}}(\mathrm{deg})^{b}$} \\
cyclo(L-Pro-L-Leu) & 64.47 & 1.064 & 79 & 1 & 0 & 0 \\
cyclo(L-Pro-D-Leu) & 69.59 & 0.982 & 7 & 90 & 2 & -25 \\
cyclo(D-Pro-L-Leu) & 70.83 & 0.970 & 14 & 4 & 82 & -6 \\
cyclo(D-Pro-D-Leu) & 64.19 & 1.069 & 0 & 5 & 16 & 89 & +19 \\
\end{tabular}

${ }^{a}$ Retention time and index of the major peak for synthetic standards. ${ }^{b}$ Measured from partial epimerized standards. ${ }^{c}$ Relative to $\mathrm{C}_{23} \mathrm{H}_{48}$ peak.

$\left.1: 1 \mathrm{v} / \mathrm{v} \mathrm{H}_{2} \mathrm{O} / \mathrm{MeOH}\right)$ in $24 \mathrm{~h}$. The decreasing positive $[\alpha]_{\mathrm{D}}$ values indicated the formation of L-prolyl-L-norvaline, which is negative. Epimerization occurs preferentially at positions 6 and 9, and it was observed that standard cyclo(L-Pro-L-Leu) epimerization was larger (21\%), followed by that of cyclo(LPro-D-Leu) (18\%), and that of cyclo(D-Pro-L-Leu) and cyclo(D-Pro-D-Leu) (both 11\%). The cis enantiomers (cyclo(L-Pro-L-Leu) and cyclo(D-Pro-D-Leu)) were harder than the trans enantiomers (cyclo(L-Pro-D-Leu) and cyclo(D-Pro-LLeu)) to separate, leading to a long chromatographic run ( 85 $\mathrm{min})$. Despite the epimerization of the synthetic standards, it was possible to determine the retention times of each stereoisomer based on the major peak. The retention times were $64.197 \mathrm{~min}$ for cyclo(D-Pro-D-Leu), $64.474 \mathrm{~min}$ for cyclo(L-Pro-L-Leu), 69.592 min for cyclo(L-Pro-D-Leu), and 70.834 min for cyclo(D-Pro-L-Leu) (Table 2).

For more reliable and reproducible standardizations we used a RRT, which overcomes the uncertainty of the identity of the analyzed substance. ${ }^{35}$ Thus, the four isomers of cyclo(ProLeu) were injected with a tricosane standard $\left(\mathrm{C}_{23} \mathrm{H}_{48}\right)$, and the calculation of RRT was performed, giving rise to the data in Table 2.

With this chromatographical separation, we could monitor the absolute configuration of the cyclo(Pro-Leu) produced by these microorganisms. C. sakazakii produced higher amounts of cyclo(L-Pro-L-Leu) compared to cyclo(D-Pro-D-Leu) and cyclo(D-Pro-L-Leu), whereas B. cereus produced cyclo(L-ProL-Leu) and cyclo(D-Pro-L-Leu). The mixed culture showed that both cultures produced the same molecules, which are depicted in Table 3. The presence of the same enantiomers in

Table 3. Relative Quantification and Optical Rotation of Natural Cyclo(Pro-Leu)

\begin{tabular}{lccccc} 
& \multicolumn{4}{c}{ cyclo } & \\
\cline { 2 - 5 } \multicolumn{1}{c}{ culture } & L-Pro-L & L-Pro-D & D-Pro-L & D-Pro-D & {$[\alpha]_{\mathrm{D}}$} \\
B. cereus & 95 & 0 & 5 & 0 & -28 \\
C. sakazakii & 86 & 0 & 12 & 2 & -21 \\
co-culture & 83 & 0 & 12 & 5 & -27 \\
\hline
\end{tabular}

different bacterial cultures can be attributed to the natural use of D-amino acids by microorganisms, or to epimerization. The epimerization percentages of $C$. sakazakii and the co-culture were similar to those of the cyclo(L-Pro-L-Leu) standard (14 and $17 \%)$, indicating a possible epimerization of the $C$. sakazakii cyclo(Pro-Leu) and not a natural occurrence.

We observed that (1) the major stereoisomer in the bacterial extracts was cyclo(L-Pro-L-Leu), and that (2) there was similar epimerization for the standards and the natural products. Therefore, the cross-talking signal responsible for a second communication system between C. sakazakii and B. cereus is cyclo(L-Pro-L-Leu).
Other DKPs. The presence of cyclo(Pro-Leu) in the cultures dominated over other polar molecules. However, other DKPs occurred in the extracts (Figure 2), that is, cyclo(ValVal) and cyclo(Pro-Leu) in the B. cereus culture, and cyclo(Val-Val), cyclo(Pro-Leu), cyclo(Leu-Leu), cyclo(Phe-Val), cyclo(Phe-Leu), and cyclo(Phe-Pro) in the C. sakazakii culture and co-culture. The fragmentation patterns are in the Supporting Information.

DKPs are able to modulate communication (QS) in microorganism cultures. DKPs and short chain AHLs bind to the same regulatory sites allowing the co-sharing of an ecological niche by different species of microorganisms. ${ }^{17}$

\section{CONCLUSIONS}

DKPs are important chemical signals in the communication between $C$. sakazakii and B. cereus. Acyl-HSL is one of the $C$. sakazakii communication signals that is easily destroyed by the action of other microorganisms (i.e., B. cereus). In contrast, cyclo(L-Pro-L-Leu) produced as a second mechanism of communication is not destroyed by Bacillus sp. enzymes and is a common signal between C. sakazakii and B. cereus. Finally, this explains why they coexist in the same industrial environment. The absolute configuration cyclo(L-Pro-L-Leu) was determined by chiral GC, which is a new tool for the absolute configuration of the four cyclo(Pro-Leu) isomers as an alternative to the joint application of NMR and Marfey's method. Further studies will evaluate the biological activity of these compounds.

\section{EXPERIMENTAL SECTION}

Unless stated otherwise, the reactions were conducted under a $\mathrm{N}_{2}$ atmosphere using reagent-grade solvents. All commercially available reagents were purchased from Sigma-Aldrich Co., Germany and were used without further purification.

Culture Conditions. B. cereus and C. sakazakii were cultivated at $30{ }^{\circ} \mathrm{C}$ in nutrient agar (NA) ("Lab-Lemco" Powder $0.1 \%$, yeast extract $0.2 \%$, peptone $0.5 \%, \mathrm{NaCl} 0.5 \%$, agar $1.5 \%$, and initial $\mathrm{pH} 7.4$ ) and grown at $30^{\circ} \mathrm{C}$ at $200 \mathrm{rpm}$ in a Luria-Bertani growth medium (tryptone $1 \%$, yeast extract $0.5 \%, \mathrm{NaCl} 1 \%$, and initial $\mathrm{pH} 7.0$ ) for $24 \mathrm{~h}$.

2,5-Diketopiperazine Extraction. C. sakazakii's 2,5Diketopiperazine (ES-DKP). C. sakazakii CCT4821 was inoculated to LB medium (1 L) and was incubated for $24 \mathrm{~h}$ at $30{ }^{\circ} \mathrm{C}$. The cells were removed by centrifugation at $3500 \mathrm{rpm}$ for $30 \mathrm{~min}$ at $4{ }^{\circ} \mathrm{C}$. The supernatant was extracted with ethyl acetate $(3 \times 300 \mathrm{~mL})$, and the solvent was evaporated under reduced pressure (Büchi Rotavapor R-200). The residue ( 80 $\mathrm{mg}$ ) was submitted to column chromatography on silica gel and eluted with a hexane/ethyl acetate gradient. The fractions were monitored by thin layer chromatography (TLC) and GC-MS. Fractions displaying characteristic DKP fragmentation [cyclo(Val-Val): $m / z$ 156, 113, 72; cyclo(Leu-Leu): $m / z$ 170, 86; 
<smiles>CC(C)C1NC(=O)C(C(C)C)NC1=O</smiles>

Cyclo(Val-Val)

2<smiles>CC(C)CC1NC(=O)C(CC(C)C)NC1=O</smiles>

Cyclo(Leu-Leu)

3<smiles>CC(C)C1NC(=O)C(Cc2ccccc2)NC1=O</smiles>

4<smiles>CC(C)CC1NC(=O)C(Cc2ccccc2)NC1=O</smiles><smiles>O=C1NC(Cc2ccccc2)C(=O)N2CCCC12</smiles>

Figure 2. Secondary DKPs found in the extract of C. sakazakii and B. cereus.

cyclo(Pro-Leu): $m / z$ 154, 86, 70; cyclo(Phe-Val): $m / z 246$, 127, 91; cyclo(Phe-Leu): $m / z$ 204, 169, 141, 91; cyclo(PhePro): $m / z 153,125,91,70]$ and adequate purity were pooled, and the solvent was evaporated. The major molecule found was cyclo(Pro-Leu), the only product completely isolated, which yielded $1.2 \mathrm{mg}$ from the $C$. sakazakii culture.

The same procedure was repeated for B. cereus CCT4060 and the co-culture of B. cereus and C. sakazakii, yielding 90 and $70 \mathrm{mg}$ of brute extract and 0.8 and $3.1 \mathrm{mg}$ of the pure DKP fraction, respectively.

Enantiomer Standards Synthesis. The production of synthetic diketopiperazine cyclo(L-Pro-L-Leu), cyclo(L-Pro-DLeu), cyclo(D-Pro-L-Leu), and cyclo(D-Pro-D-Leu) was carried out by solid phase peptide synthesis (SPPS) with the Fmoc (9-fluorenylmethyloxycarbonyl) strategy. A total of 100 $\mathrm{mg}$ of Wang resin (Sigma-Aldrich) already coupled with L- or Dleucine-Fmoc-OH $\left(0.7 \mathrm{mmol} / \mathrm{g}_{\text {resin }}\right)$ was submitted to a $3 \mathrm{~mL}$ dichloromethane (DCM) bath for $20 \mathrm{~min}$ for activation. Next, $3 \mathrm{~mL}$ of 4-methylpiperidine was poured into the reaction flask and stirred for $20 \mathrm{~min}$, twice. After vacuum filtration, the resin was washed with $3 \mathrm{~mL}$ of methanol and $3 \mathrm{~mL}$ of DCM, three times each. The solvents were removed with vacuum filtration.

L- or D-Proline-Fmoc-OH (Sigma-Aldrich) was added to the system in 3:1 mmol equivalency in relation to L-leucine-Fmoc. 1-Hydroxybenzotriazole hydrate (Sigma-Aldrich) and $N, N^{\prime}$ diisopropylcarbodiimide (DIC), dissolved in $3 \mathrm{~mL}$ of dimethylformamide, were added to the system in $6: 1$ proportions relative to the quantity of amino acid coupled to the resin ( $\mathrm{mmol})$. The system was stirred for $4 \mathrm{~h}$ at room temperature, and afterwards, it was vacuum filtered. The procedure of deprotection of proline was repeated to assure the availability of the amino terminal for spontaneous cyclization.

After vacuum filtration to remove the reactants, $3 \mathrm{~mL}$ of the cleavage cocktail (95\% trifluoroacetic acid, 2.5\% triisopropylsilane, and $2.5 \%$ distilled water) was added to the system and stirred for $4 \mathrm{~h}$ at room temperature. Filtration and evaporation (Büchi Rotavapor R-200) produced a colorless oil (24 mg) that was dissolved in methanol and analyzed by GC-MS.

Cyclo(L-Pro-L-Leu). (3S, 8aS)-3-isobutylhexahydropyrrolo$[1,2-\alpha]$ pyrazine-1,4-dione $(24 \mathrm{mg})$

TLC (hexane/ethyl acetate/methanol, stain solution: phosphomolybdic acid $\left(10 \% \mathrm{~m} / \mathrm{v}\right.$ in ethanol) $R_{\mathrm{f}} 0.25$.

$[\boldsymbol{\alpha}]_{\mathrm{D}}-25\left(c=0.1 \mathrm{~g} / 100 \mathrm{~mL}, 20^{\circ} \mathrm{C}, \mathrm{MeOH}\right)$;

${ }^{1} \mathrm{H}$ NMR (400.18 MHz, CD $\left.3 \mathrm{OD}, \delta_{\mathrm{CD}_{3} \mathrm{OD}} 3.31 \mathrm{ppm}\right): \delta 4.45$ $(1 \mathrm{H}, \mathrm{dd}, J=9.7$ and $5.5 \mathrm{~Hz}, \mathrm{H}-6), 4.31(1 \mathrm{H}, \mathrm{dd}, J=8.6$ and 6.3
Hz, H-9), 3.42 (1H, m, H-3a), 3.34 (1H, m, H-3b), 2.45 (1H, m, H-5b), 2.15 (1H, m, H-5a), $2.05(2 \mathrm{H}, \mathrm{m}, \mathrm{H}-4), 1.73(1 \mathrm{H}, \mathrm{m}$, $\mathrm{H}-11), 1.65$ (2H, m, H-10), 0.98 ( $3 \mathrm{H}, \mathrm{d}, J=6.3 \mathrm{~Hz}, \mathrm{H}-12)$, $0.94(3 \mathrm{H}, \mathrm{d}, J=6.2 \mathrm{~Hz}, \mathrm{H}-13)$.

${ }^{13} \mathrm{C}$ NMR (100.63 MHz, $\left.\mathrm{CD}_{3} \mathrm{OD}, \delta_{\mathrm{CD}_{3} \mathrm{OD}} 49.15 \mathrm{ppm}\right): \delta$ 175.5 (C, C-7), 170.0 (C, C-1), 61.1 (CH, C-6), 52.6 (CH, C9), $47.6\left(\mathrm{CH}_{2}, \mathrm{C}-3\right), 41.4\left(\mathrm{CH}_{2}, \mathrm{C}-10\right), 31.1\left(\mathrm{CH}_{2}, \mathrm{C}-5\right), 26.2$ (CH, C-11), $25.0\left(\mathrm{CH}_{2}, \mathrm{C}-4\right), 23.5\left(\mathrm{CH}_{3}, \mathrm{C}-12\right), 21.8\left(\mathrm{CH}_{3}\right.$, $\mathrm{C}-13)$.

EI/MS (70 eV) $m / z$ (relative intensity): $210\left(\mathrm{M}^{\bullet+}\right), 154$ (99); 70 (47), 86 (13), 125 (9), 155 (8), 124 (7), 69 (6), 55 (5), 68 (5), 96(4).

Cyclo(L-Pro-D-Leu). (3R, 8aS)-3-isobutylhexahydropyrrolo$[1,2-\alpha]$ pyrazine-1,4-dione $(20 \mathrm{mg})$

TLC (hexane/ethyl acetate/methanol, stain solution: phosphomolybdic acid $\left(10 \% \mathrm{~m} / \mathrm{v}\right.$ in ethanol)) $R_{\mathrm{f}} 0.25$.

$[\boldsymbol{\alpha}]_{\mathrm{D}}-6\left(c=0.1 \mathrm{~g} / 100 \mathrm{~mL}, 20^{\circ} \mathrm{C}, \mathrm{MeOH}\right)$;

${ }^{1} \mathrm{H}$ NMR (400.18 MHz, CD $3 \mathrm{OD}, \delta_{\mathrm{CD}_{3} \mathrm{OD}} 3.31 \mathrm{ppm}$ ): $\delta 4.45$ (1H, m, H-6), 4.29 (1H, m, H-9), 3.38 (2H, m, H-3a and $-3 \mathrm{~b})$, 2.47 (1H, m, H-5b), 2.03 (3H, m, H-5a and -4$), 1.68(3 \mathrm{H}, \mathrm{m}$, $\mathrm{H}-10$ and -11$), 0.98$ (3H, d, $J=6.0 \mathrm{~Hz}, \mathrm{H}-12), 0.93(3 \mathrm{H}, \mathrm{d}, J=$ $6.1 \mathrm{~Hz}, \mathrm{H}-13)$.

${ }^{13} \mathrm{C}$ NMR $\left(100.63 \mathrm{MHz}, \mathrm{CD}_{3} \mathrm{OD}, \delta_{\mathrm{CD}_{3} \mathrm{OD}} 49.15 \mathrm{ppm}\right): \delta$ 175.6 (C, C-7), 169.9 (C, C-1), 61.3 (CH, C-6), 52.5 (CH, C9), $47.5\left(\mathrm{CH}_{2}, \mathrm{C}-3\right), 41.6\left(\mathrm{CH}_{2}, \mathrm{C}-10\right), 31.4\left(\mathrm{CH}_{2}, \mathrm{C}-5\right), 26.4$ $(\mathrm{CH}, \mathrm{C}-11), 25.2\left(\mathrm{CH}_{2}, \mathrm{C}-4\right), 23.5\left(\mathrm{CH}_{3}, \mathrm{C}-12\right), 21.8\left(\mathrm{CH}_{3}\right.$, $\mathrm{C}-13)$.

EI/MS $(70 \mathbf{~ e V}) \mathrm{m} / z$ (relative intensity): $210\left(\mathrm{M}^{\bullet+}\right), 154$ (99); 70 (51), 125 (17), 124 (12), 86 (10), 155 (8), 69 (6), 68 (6), 96 (5), 98 (5).

Cyclo(D-Pro-L-Leu). (3S, 8aR)-3-isobutylhexahydropyrrolo$[1,2-\alpha]$ pyrazine-1,4-dione $(30 \mathrm{mg})$

TLC (hexane/ethyl acetate/methanol, stain solution: phosphomolybdic acid $\left(10 \% \mathrm{~m} / \mathrm{v}\right.$ in ethanol) $R_{\mathrm{f}} 0.25$.

$[\boldsymbol{\alpha}]_{\mathrm{D}}+19\left(c=0.1 \mathrm{~g} / 100 \mathrm{~mL}, 20^{\circ} \mathrm{C}, \mathrm{MeOH}\right)$;

${ }^{1} \mathrm{H}$ NMR (400.18 MHz, $\left.\mathrm{CD}_{3} \mathrm{OD}, \delta_{\mathrm{CD}_{3} \mathrm{OD}} 3.31 \mathrm{ppm}\right): \delta 4.45$ (1H, m, H-6), 4.30 (1H, dd, $J=8.8$ and $7.1 \mathrm{~Hz}, \mathrm{H}-9), 3.38(2 \mathrm{H}$, m, H-3), 2.45 (1H, m, H-5b), 2.03 (3H, m, H-4 and $-5 a), 1.68$ $(3 \mathrm{H}, \mathrm{m}, \mathrm{H}-10$ and -11$), 0.98(3 \mathrm{H}, \mathrm{d}, J=6.1 \mathrm{~Hz}, \mathrm{H}-12), 0.93$ $(3 \mathrm{H}, \mathrm{d}, J=6.2 \mathrm{~Hz}, \mathrm{H}-13)$.

${ }^{13} \mathrm{C}$ NMR (100.63 MHz, $\left.\mathrm{CD}_{3} \mathrm{OD}, \delta_{\mathrm{CD}_{3} \mathrm{OD}} 49.15 \mathrm{ppm}\right): \delta$ 175.6 (C, C-7), 169.9 (C, C-1), 61.3 (CH, C-6), 52.5 (CH, C9), $47.5\left(\mathrm{CH}_{2}, \mathrm{C}-3\right), 41.6\left(\mathrm{CH}_{2}, \mathrm{C}-10\right), 31.4\left(\mathrm{CH}_{2}, \mathrm{C}-5\right), 26.4$ 
(CH, C-11), $25.2\left(\mathrm{CH}_{2}, \mathrm{C}-4\right), 23.5\left(\mathrm{CH}_{3}, \mathrm{C}-12\right), 21.8\left(\mathrm{CH}_{3}\right.$, C-13).

EI/MS (70 eV) $m / z$ (relative intensity): $210\left(\mathrm{M}^{\bullet+}\right), 154$ (99); 70 (53), 98 (26), 125 (18), 124 (12), 86 (11), 155 (8), 68 (6), 96 (6), $55(6)$.

Cyclo(D-Pro-D-Leu). (3R, 8aR)-3-isobutylhexahydropyrrolo$[1,2-\alpha]$ pyrazine-1,4-dione $(17 \mathrm{mg})$

TLC (hexane/ethyl acetate/methanol, stain solution: phosphomolybdic acid $(10 \% \mathrm{~m} / \mathrm{v}$ in ethanol $)) R_{\mathrm{f}} 0.28$.

$[\boldsymbol{\alpha}]_{\mathrm{D}}+28\left(c=0.1 \mathrm{~g} / 100 \mathrm{~mL}, 20{ }^{\circ} \mathrm{C}, \mathrm{MeOH}\right)$;

${ }^{1} \mathrm{H}$ NMR (400.18 MHz, CD $\mathrm{CD}_{3} \mathrm{OD} \delta_{\mathrm{CD}_{3} \mathrm{OD}} 3.31 \mathrm{ppm}$ ): $\delta 4.45$ $(1 \mathrm{H}, \mathrm{dd}, J=9.7$ and $5.4 \mathrm{~Hz}, \mathrm{H}-6), 4.31(1 \mathrm{H}, \mathrm{dd}, J=8.6$ and 6.4 $\mathrm{Hz}, \mathrm{H}-9), 3.42$ (1H, m, H-3a), 3.35 (1H, m, H-3b), $2.45(1 \mathrm{H}$, m, H-5b), 2.15 (1H, m, H-5a), $2.04(2 \mathrm{H}, \mathrm{m}, \mathrm{H}-4), 1.68(3 \mathrm{H}, \mathrm{m}$, $\mathrm{H}-10$ and -11$), 0.98(3 \mathrm{H}, \mathrm{d}, J=6,3 \mathrm{~Hz}, \mathrm{H}-12), 0.94(3 \mathrm{H}, \mathrm{d}, J=$ $6.1 \mathrm{~Hz}, \mathrm{H}-13)$.

${ }^{13} \mathrm{C}$ NMR (100.63 MHz, $\left.\mathrm{CD}_{3} \mathrm{OD}, \delta_{\mathrm{CD}_{3} \mathrm{OD}} 49.15 \mathrm{ppm}\right): \delta$ 175.5 (C, C-7), 170.0 (C, C-1), 61.1 (CH, C-6), 52.6 (CH, C9), $47.6\left(\mathrm{CH}_{2}, \mathrm{C}-3\right), 41.4\left(\mathrm{CH}_{2}, \mathrm{C}-10\right), 31.1\left(\mathrm{CH}_{2}, \mathrm{C}-5\right), 26.2$ $(\mathrm{CH}, \mathrm{C}-11), 25.0\left(\mathrm{CH}_{2}, \mathrm{C}-4\right), 23.5\left(\mathrm{CH}_{3}, \mathrm{C}-12\right), 21.8\left(\mathrm{CH}_{3}\right.$, C-13).

EI/MS (70 eV) $m / z$ (relative intensity): $210\left(\mathrm{M}^{\bullet+}\right), 154$ (99); 70 (43), 86 (14), 155 (9), 125 (8), 124 (8), 69 (6), 68 (6), 55 (5), 139 (5).

Identification and Structure Elucidation. GC-Mass Spectrometry (GC-MS). GC-MS was performed with an Agilent 6890 gas chromatograph (Santa Clara, CA) coupled with a Hewlett-Packard 5973 mass spectrometer, equipped with a capillary column $(30 \mathrm{~m} \times 0.25 \mathrm{~mm}$ i.d. $\times 0.25 \mu \mathrm{m}$ film thickness) coated with silica in splitless mode. The injector temperature was $270{ }^{\circ} \mathrm{C}$, and the carrier gas $(\mathrm{He})$ flow was 1 $\mathrm{mL} / \mathrm{min}$. One microliter samples $(1 \mathrm{mg} / \mathrm{mL})$ in ethyl acetate were injected into the GC-MS. The oven temperature program was as follows: initial temperature of $150{ }^{\circ} \mathrm{C}$ for 3 min; increasing the temperature from 150 to $275{ }^{\circ} \mathrm{C}$ at $25^{\circ} \mathrm{C} /$ min; and maintaining the temperature of $275^{\circ} \mathrm{C}$ for $10 \mathrm{~min}$. The MS conditions included an ionization energy of $0.7 \mathrm{kV}$. Analysis was conducted in full scan mode $(\mathrm{m} / z$ 40-400). Spectral interpretation was aided by the National Institute of Standards and Technology (NIST) 05 spectral library stored in the GC-MS controller unit.

${ }^{1} \mathrm{H} N M R$ and ${ }^{13} \mathrm{C} N M R$. ${ }^{1} \mathrm{H}$ NMR spectra were recorded on Bruker spectrometers $(400 \mathrm{MHz})$. Chemical shifts are reported in parts per million ( $\mathrm{ppm}$ ) relative to the residual solvent peaks ( $\mathrm{CD}_{3} \mathrm{OD} \delta 3.30$ and $4.84 \mathrm{ppm}$ ). ${ }^{1} \mathrm{H}$ NMR coupling constants $(J)$ are reported in hertz $(\mathrm{Hz})$, and multiplicity is indicated as follows: s (singlet), $\mathrm{d}$ (doublet), $\mathrm{t}$ (triplet), $\mathrm{q}$ (quartet), $\mathrm{qt}$ (quintet), m (multiplet), brs (broad singlet), and dd (doublet of doublet). ${ }^{13} \mathrm{C}$ NMR spectra were recorded at $100 \mathrm{MHz}$, and all chemical shift values are reported in ppm, using the signal at $\delta 49.15$ ppm as the internal reference.

Absolute Configuration of Compounds. A chiral Lipodex-E fused silica capillary column (octakis-(3-O-butyryl-2,6-di-O-npentyl)- $\gamma$-cyclodextrin) (28 m length, $0.25 \mathrm{~mm}$ I.D., film thickness of $12 \mu \mathrm{m}$ ) was installed on an Agilent GC-FID Model 6850. The run started at $120^{\circ} \mathrm{C}$ for $5 \mathrm{~min}$ and then it increased $1{ }^{\circ} \mathrm{C} / \mathrm{min}$ to $180{ }^{\circ} \mathrm{C}$ and stood for $20 \mathrm{~min}$. The four enantiomeric standards, as well as the samples of each culture and co-culture, were injected at $1 \mathrm{mg} / \mathrm{mL}$. The enantiomers were also injected separately to determine the retention time for comparison with those of the natural ones to determine their absolute configurations. RRT was obtained by co-injecting tricosane $\left(\mathrm{C}_{23} \mathrm{H}_{48}, \mathrm{RT}\right.$ 68.649) with the standards and calculated using eq 1 .

$$
\mathrm{RRT}=\frac{\text { standard retention }(\mathrm{min})}{\text { sample retention }(\mathrm{min})}
$$

Optical Rotation. Optical rotations were measured at $20^{\circ} \mathrm{C}$ on a PerkinElmer 341 polarimeter at $589 \mathrm{~nm}$ using PerkinElmer $10-\mathrm{mm}$ cuvettes. The concentrations (c) are expressed in $\mathrm{g} / 100 \mathrm{~mL}$.

\section{ASSOCIATED CONTENT}

\section{Supporting Information}

The Supporting Information is available free of charge on the ACS Publications website at DOI: 10.1021/acsomega.6b00513.

GC chromatograms, EI mass spectra, ${ }^{1} \mathrm{H}$ and ${ }^{13} \mathrm{C}$ NMR, including 2D NMR spectra, and chiral GC chromatograms for four synthetic standards of cyclo(Pro-Leu) stereoisomers, natural cyclo(Pro-Leu) from B. cereus, $C$. sakazakii, and the co-culture of both, and other DKPs found in individual and co-cultures (PDF)

\section{AUTHOR INFORMATION}

\section{Corresponding Author}

*E-mail: anita@iqm.unicamp.br, anita.marsaioli@gmail.com. ORCID

Anita J. Marsaioli: 0000-0002-7894-6942

Notes

The authors declare no competing financial interest.

\section{ACKNOWLEDGMENTS}

The authors are grateful for financial support from Fundação de Amparo à Pesquisa do Estado de São Paulo (FAPESP), Conselho Nacional de Desenvolvimento Científico e Tecnológico $(\mathrm{CNPq})$, and Coordenação de Aperfeiçoamento de Pessoal de Nivel Superior (CAPES).

\section{REFERENCES}

(1) Yan, Q.; Power, K. A.; Tall, B. D.; Fanning, S. Cronobacter Spp. (Formerly Enterobacter sakazakii). In Guide to Foodborne Pathogenics; John Wiley \& Sons, Inc., 2013; pp 241-256.

(2) Van Houdt, R.; Aertsen, A.; Jansen, A.; Quintana, A. L.; Michiels, C. W. Biofilm Formation and Cell-to-Cell Signalling in Gram-Negative Bacteria Isolated from a Food Processing Environment. J. Appl. Microbiol. 2004, 96, 177-184.

(3) Fuqua, C.; Greenberg, E. P. Signalling: Listening in on Bacteria: Acyl-Homoserine Lactone Signalling. Nat. Rev. Mol. Cell Biol. 2002, 3, 685-695.

(4) Lehner, A.; Riedel, K.; Eberl, L.; Breeuwer, P.; Diep, B.; Stephan, R. Biofilm Formation, Extracellular Polysaccharide Production, and Cell-to-Cell Signaling in Various Enterobacter sakazakii Strains: Aspects Promoting Environmental Persistence. J. Food Prot. 2005, $68,2287-2294$

(5) Araújo, F. D. D. S.; Esper, L. M. R.; Kuaye, A. Y.; Sircili, M. P.; Marsaioli, A. J. N-Acyl-Homoserine Lactones from Enterobacter sakazakii (Cronobacter Spp.) and Their Degradation by Bacillus cereus Enzymes. J. Agric. Food Chem. 2012, 60, 585-592.

(6) Pinto, U. M.; de Souza Viana, E.; Martins, M. L.; Vanetti, M. C. D. Detection of Acylated Homoserine Lactones in Gram-Negative Proteolytic Psychrotrophic Bacteria Isolated from Cooled Raw Milk. Food Control 2007, 18, 1322-1327.

(7) Bottone, E. J. Bacillus cereus, a Volatile Human Pathogen. Clin. Microbiol. Rev. 2010, 23, 382-398. 
(8) Hsueh, Y. H.; Somers, E. B.; Lereclus, D.; Wong, A. C. L. Biofilm Formation by Bacillus cereus Is Influenced by PlcR, a Pleiotropic Regulator. Appl. Environ. Microbiol. 2006, 72, 5089-5092.

(9) Vidal-martins, A. M. C.; Durival, O.; Júnior, R.; Bürger, K. P.; Cardozo, M. V.; Salloti, B. M.; Lígia, A.; Cortez, L. Enterotoxigenics Bacillus cereus in Differents Phases of the UHT Milk Process. Rev. Bras. Clin. Vet. 2006, 13, 32-36.

(10) Kumar, S. N.; Mohandas, C.; Nambisan, B.; Sreerag, R. S.; Jayaprakas, C. A. Cyclo(L-Pro-D-Arg): A New Antibacterial and Antitumour Diketopiperazine from Bacillus cereus Associated with a Rhabditid Entomopathogenic. Folia Microbiol. 2014, 59, 197-202.

(11) Kumar, S. N.; Mohandas, C.; Nambisan, B. Purification of an Antifungal Compound, Cyclo(1-Pro-D-Leu) for Cereals Produced by Bacillus cereus Subsp. Thuringiensis Associated with Entomopathogenic Nematode. Microbiol. Res. 2013, 168, 278-288.

(12) Yan, P.-S.; Song, Y.; Sakuno, E.; Nakajima, H.; Nakagawa, H.; Yabe, K. Cyclo (L-Leucyl-L-Prolyl) Produced by Achromobacter xylosoxidans Inhibits Aflatoxin Production by Aspergillus parasiticus. Appl. Environ. Microbiol. 2004, 70, 7466-7473.

(13) Gao, Y.; Yu, L.; Peng, C.; Li, Z.; Guo, Y. Diketopiperazines from Two Strains of South China Sea Sponge-Associated Microorganisms. Biochem. Syst. Ecol. 2010, 38, 931-934.

(14) Mangamuri, U. K.; Muvva, V.; Poda, S.; Manavathi, B.; Bhujangarao, C.; Yenamandra, V. Chemical Characterization \& Bioactivity of Diketopiperazine Derivatives from the Mangrove Derived Pseudonocardia endophytica. Egypt. J. Aquat. Res. 2016, 42, 169-175.

(15) Brack, C.; Mikolasch, A.; Schauer, F. 2,5-Diketopiperazines Produced by Bacillus pumilus During Bacteriolysis of Arthrobacter citreus. Mar. Biotechnol. 2014, 16, 385-395.

(16) Guo, X.; Liu, X.; Pan, J.; Yang, H. Synergistic Algicidal Effect and Mechanism of Two Diketopiperazines Produced by Chryseobacterium Sp. Strain GLY-1106 on the Harmful Bloom-Forming Microcystis aeruginosa. Sci. Rep. 2015, 5, No. 14720.

(17) Holden, M. T.; Ram Chhabra, S.; de Nys, R.; Stead, P.; Bainton, N. J.; Hill, P. J.; Manefield, M.; Kumar, N.; Labatte, M.; England, D.; Rice, S.; Givskov, M.; Salmond, G. P.; Stewart, G. S.; Bycroft, B. W.; Kjelleberg, S.; Williams, P. Quorum-Sensing Cross Talk: Isolation and Chemical Characterization of Cyclic Dipeptides from Pseudomonas aeruginosa and Other Gram-Negative Bacteria. Mol. Microbiol. 1999, 33, 1254-1266.

(18) Degrassi, G.; Aguilar, C.; Bosco, M.; Zahariev, S.; Pongor, S.; Venturi, V. Plant Growth-Promoting Pseudomonas putida WCS358 Produces and Secretes Four Cyclic Dipeptides: Cross-Talk with Quorum Sensing Bacterial Sensors. Curr. Microbiol. 2002, 45, 250254.

(19) Stierle, D. B.; Faulkner, D. J. Antimicrobial N-Methylpyridinium Salts Related to the Xestamines from the Caribbean Sponge Calyx podatypa. J. Nat. Prod. 1991, 54, 1134-1136.

(20) Johnson, J. L.; Jackson, W. G.; Eble, T. E. Isolation of L-LeucylL-Proline Anhydride from Microbiological Fermentations. J. Am. Chem. Soc 1951, 73, 2947-2948.

(21) He, R.; Wang, B.; Wakimoto, T.; Wang, M.; Zhu, L.; Abe, I. Cyclodipeptides from Metagenomic Library of a Japanese Marine Sponge. J. Braz. Chem. Soc. 2013, 24, 1926-1932.

(22) Soledade, M.; Pedras, C.; Yu, Y.; Liu, J.; Tandron-Moya, Yu. A. Metabolites Produced by the Phytopathogenic Fungus Rhizoctonia solani: Isolation, Chemical Structure Determination, Syntheses and Bioactivity. Z. Naturforsch., C: J. Biosci. 2005, 60, 5-10.

(23) Siemion, I. Z. Nmr-Untersuchungen Bei Prolin- Enthaltenden Diketopiperazinen. Org. Magn. Reson. 1971, 3, 545-550.

(24) Kumar, S. N.; Mohandas, C.; Siji, J. V.; Rajasekharan, K. N.; Nambisan, B. Identification of Antimicrobial Compound, Diketopiperazines, from a Bacillus Sp. N Strain Associated with a Rhabditid Entomopathogenic Nematode against Major Plant Pathogenic Fungi. J. Appl. Microbiol. 2012, 113, 914-924.

(25) Dong, Y.; Cui, C. B.; Li, C. W.; Hua, W.; Wu, C. J.; Zhu, T. J.; $\mathrm{Gu}, \mathrm{Q}$. Q. Activation of Dormant Secondary Metabolite Production by
Introducing Neomycin Resistance into the Deep-Sea Fungus, Aspergillus versicolor ZBY-3. Mar. Drugs 2014, 12, 4326-4352.

(26) Loffet, A. Peptides. In Peptides 1976. Proceedings of the Fourteenth European Peptide Symposium; Ed de l'Université de Bruxelles, 1976; pp 641-646.

(27) Fischer, E.; Reif, G. Derivate Des Prolins. Justus Liebigs Ann. Chem. 1908, 363, 118.

(28) Huang, R. M.; Ma, W.; Dong, J. D.; Zhou, X. F.; Xu, T.; Lee, K. J.; Yang, X.; Xu, S. H.; Liu, Y. A New 1,4-Diazepine from South China Sea Marine Sponge Callyspongia Species. Molecules 2010, 15, 871877.

(29) Wegerski, C. J.; France, D.; Cornell-Kennon, S.; Crews, P. Using a Kinase Screen to Investigate the Constituents of the Sponge Stelletta clavosa Obtained from Diverse Habitats. Bioorg. Med. Chem. 2004, 12, $5631-5637$.

(30) Adamczeski, M.; Reed, A. R.; Crews, P. New and Known Diketopiperazinres from the Caribean Sponge Calyx CF. Podatypa. J. Nat. Prod. 1995, 58, 201.

(31) Yonezawa, K.; Yamada, K.; Kouno, I. New Diketopiperazine Derivatives Isolated from Sea Urchin-Derived Bacillus Sp. Chem. Pharm. Bull. 2011, 59, 106-108.

(32) Lee, S.; Tamayo-Castillo, G.; Pang, C.; Clardy, J.; Cao, S.; Kim, K. H. Diketopiperazines from Costa Rican Endolichenic Fungus Colpoma Sp. CR1465A. Bioorg. Med. Chem. Lett. 2016, 26, 24382441.

(33) Marfey, P. Determination of D-Amino Acids. II. Use of a Bifunctional Reagent, 1,5-Difluoro-2,4-Dinitrobenzene. Carlsberg Res. Commun. 1984, 49, 591-596.

(34) Eguchi, C.; Kakuta, A. Studies on Cyclic Dipeptides. I. Thermodynamics of the Cis-Trans Isomerization of the Side Chains in Cyclic Dipeptides. J. Am. Chem. Soc. 1974, 96, 3985.

(35) Jenke, D.; Liu, N. Chromatographic Considerations in the Standardization of Liquid Chromatographic Methods Used for Extractables Screening. J. Liq. Chromatogr. Relat. Technol. 2016, 6076, 613-619. 